\title{
A educação que vem do lixo: Um estudo do programa "Piedade sem lixo" e a formação da cidadania ambiental
}

Renata Nascimento Fernandes ${ }^{1}$

\begin{abstract}
RESUMO: Este trabalho tem o objetivo de analisar a questão da preservação do meio ambiente, a necessidade de educação ambiental e o desenvolvimento sustentável. Para tanto, foi feita uma pesquisa no projeto de Educação Ambiental realizado no município mineiro de Piedade do Rio Grande, denominado "Piedade sem Lixo" e os efeitos conquistados na sua execução. Juntamente com uma revisão literária sobre o tema, constata-se que a educação para a cidadania, que representa a possibilidade de motivar as pessoas na transformação das diversas formas de participação na defesa da qualidade de vida, proporciona a preservação da biodiversidade presente no planeta Terra.
\end{abstract}

Palavras - chave: educação ambiental; desenvolvimento sustentável; cidadania.

\section{INTRODUÇÃO}

Em tempos atuais, a quantidade de informação que a população recebe assume um papel cada vez mais relevante, seja no entretenimento, seja na formação da intelectualidade, e por fim na educação. Com isso, a educação assume um papel importante na formação da cidadania ambiental que tem, em seu papel principal, motivar e sensibilizar as pessoas para transformar as diversas formas de participação na defesa da qualidade de vida.

A dimensão da crise ambiental tem sido refletida em diversos aspectos da sociedade, como na mídia, na escola, nas empresas e até mesmo no próprio cotidiano dos indivíduos. A necessidade de uma busca de soluções que minimizem os impactos dessa crise ambiental entrou em pauta nas discussões desses organismos, como a realização de congressos, divulgação do tema em revistas, rádio, TV e internet e até mesmo simples ações, promovidas pela sociedade, como palestras, dinâmicas educacionais com crianças, envolvimento de funcionários de empresas com o tema e que, de forma geral, conseguem uma conscientização da população como um todo.

É preciso lembrar, no entanto, que as medidas tomadas para essa conscientização acontecem à longo prazo e principalmente através de reflexões críticas e práticas educacionais. Existem muitos trabalhos que relacionam prática educacional e Meio Ambiente, Carvalho e outros (2009) identificam que os relatos das pesquisas empíricas estão, na maioria das vezes, relacionados às práticas educacionais dentro e fora do contexto escolar.

O tema Educação Ambiental tem sido tratado nos vários âmbitos da sociedade; as administrações municipais e demais segmentos, como ONG's, órgãos privados e escolas, estão preocupados com ações do tipo saneamento ambiental e conscientização da população para melhorias e alternativas ambientais interessantes. Um ponto essencial e 
considerado por vários especialistas como um grande problema de todos os municípios é a disposição inadequada dos resíduos e uma medida simples é a implementação da Coleta Seletiva, que deve ser garantida e realizada como o primeiro passo para uma Educação Ambiental plena. No entanto, é fato observado por Fagundes (2009) que muitos municípios brasileiros se limitam a varrer as ruas e recolher o lixo domiciliar depositando-os em locais distantes, verdadeiros lixões, sem a mínima preocupação com os cuidados dos resíduos.

Neste artigo pretende-se demonstrar que em um pequeno município de Minas Gerais a administração municipal busca melhorias para a disposição dos resíduos, conseguindo medidas e o apoio junto à população. $E$ tem também o objetivo de discutir as questões levantadas acima e relacioná-las com o estudo de caso realizado no município de Piedade do Rio Grande - MG; o projeto intitulado "Piedade sem Lixo" tem em seu objetivo promover a educação ambiental na cidade e identifica-se experiências e aprendizados mútuos, dentro e fora do contexto escolar. Nesse sentido, o enfoque em trabalhos conceituados sobre o tema será conciliado com a visão prática da vivência do projeto. Esse artigo se justifica pelo fato de não haver um estudo pontual sobre a questão levantada no município recortado e também a necessidade de se divulgar o quanto tais projetos são importantes para a construção da cidadania.

\section{DESENVOLVIMENTO}

Refletir sobre a complexidade dos problemas ambientais da atualidade abre uma estimulante oportunidade para compreender a gestão de novos atores sociais que se mobilizam para a apropriação da natureza, para um processo educativo articulado e compromissado com a sustentabilidade e a participação, apoiado numa lógica que privilegia o diálogo e a interdependência das diferentes áreas do saber. Mas também, questiona valores e premissas que norteiam as práticas sociais prevalecentes, implicando mudança na forma de pensar e transformação no conhecimento e nas práticas educativas.

Cabe destacar que a educação ambiental assume cada vez mais uma função transformadora, na qual a responsabilidade dos indivíduos torna-se um objetivo essencial. Entende-se, portanto, que a educação ambiental é condição necessária para modificar um quadro de crescente degradação sócio-ambiental, mas ela ainda não é suficiente, o que, no dizer de Tamaio, se converte em "mais uma ferramenta de mediação necessária entre culturas, comportamentos diferenciados e interesses de grupos sociais para a construção das transformações desejadas" (TAMAIO, 2000, p. 38). O educador tem a função de mediador na construção de referenciais ambientais e deve saber usá-los como instrumentos para o desenvolvimento de uma prática social centrada no conceito da natureza. Para Jacobi (2003) a educação ambiental deve ser vista como um processo de permanente aprendizagem que valoriza as diversas formas de conhecimento e forma cidadãos com consciência local e planetária.

Cidadania tem a ver com a identidade e o pertencimento a uma coletividade. José Murilo de Carvalho (2002) ao analisar a cidadania no Brasil afirma que o cidadão é aquele que respeita e participa das decisões da sociedade e é divulgada através dos meios de comunicação e instituições de ensino. A educação ambiental como formação e exercício de cidadania refere-se a uma nova forma de encarar a relação do homem com a natureza, baseada numa nova ética, que pressupõe outros valores morais e uma forma diferente de ver o mundo e os homens. Portanto, gestos como não jogar papel na rua, não desmatar, cuidar da disposição do lixo, não poluir, preservar a fauna, flora, rios, mares e tantos outros gestos formam cidadãos ativos e participantes na construção da sociedade.

A educação ambiental nasce como um processo educativo que conduz a um saber ambiental materializado nos valores éticos e nas regras políticas de convívio social. Ela deve, portanto, ser direcionada para a cidadania ativa considerando seu sentido de pertencimento 
e responsabilidade que, por meio da ação coletiva e organizada, busca a compreensão e a superação das causas estruturais e conjunturais dos problemas ambientais.

Conforme Layargues (2002), diante de uma sociedade moderna e industrializada, a maneira mais simplificada de mostrar como iniciar a educação ambiental é a Coleta seletiva ao invés da Coleta convencional, em que vem se destacando as latas de alumínio - material mais reciclado. Para Abrão e outros (2000) coleta seletiva é a separação dos materiais recicláveis, como papéis, vidros, plásticos e metais, do restante do lixo.

O gerenciamento dos resíduos no Brasil é um grande desafio para os administradores municipais, assim como para toda a população. De acordo com Savi (2005), há necessidade de priorizar e definir políticas que envolvam todos os níveis de governo, ou seja, municipal, estadual e federal, e também os variados setores públicos, privados e ONG's. Para Pereira citado por Junkes (PEREIRA apud JUNKES, 2002), 90\% da poluição no Brasil tem origem orgânica através da disposição inadequada de resíduos sólidos orgânicos em lixões e aterros mal controlados.

Uma das ONG's mais bem sucedidas na questão do lixo é a "Doe seu lixo", que além de se preocupar com a questão da reciclagem, ainda trabalha a sustentabilidade no seu todo - com programas de inclusão social, de parcerias com grandes nomes do setor privado, financiar e fomentar entidades de preservação e educação ambiental. Porém, não só as ONG's podem se dedicar a esse papel, pois é necessário existir um processo político e público para esse processo enorme de educação e, esse mesmo processo deve ser acompanhado da criação das políticas públicas de sustentabilidade.

A noção de sustentabilidade implica uma "inter-relação necessária de justiça social, qualidade de vida, equilíbrio ambiental e a ruptura com o atual padrão de desenvolvimento" (JACOBI, 2003, p. 196). Ainda para o autor (JACOBI, 2003), o desenvolvimento sustentável somente pode ser entendido como um processo no qual, de um lado, as restrições mais relevantes estão relacionadas com a exploração dos recursos, a orientação do desenvolvimento tecnológico e o marco institucional. De outro lado, o crescimento deve enfatizar os aspectos qualitativos, relacionados com a eqüidade, o uso de recursos em particular da energia e a geração de resíduos e contaminantes. Segundo Muller (2001) o desenvolvimento somente será sustentável se for simultaneamente competitivo, eqüitativo e ecológico.

Para Fernandez (2005), apesar da popularidade do termo desenvolvimento sustentável, é crucial fazê-lo realidade, pois se desejamos um mundo melhor e qualidade de vida para nossos filhos, cabe a nós buscar melhoria para haver preservação do meio ambiente, e para isso faz-se necessário usar os recursos naturais de maneira sustentável, mesmo que haja controvérsia no que diz respeito ao desenvolvimento econômico, de um país, seja ele de primeiro ou terceiro mundo.

Nesse sentido Brugger (2006) lembra que a busca pelas interdisciplinas é uma maneira de relacionar sociedade e natureza, buscando o equilíbrio entre ambas e podendo alcançar a sustentabilidade. Jacobi (2003) esclarece que a educação ambiental deve ser vista como um processo permanente de aprendizagem, que valoriza as diversas formas de conhecimento e forma cidadãos com consciência local e planetária. Vasconcelos e outros (2009) demonstram que a educação ambiental provoca mudanças políticas e estimulam uma racionalidade ética e ecológica, se consolidando na área da política no Brasil, para além do campo universitário, em diversos espaços educativos formais e não formais, ampliando seus horizontes e tendo uma intervenção social transformadora. Acredita-se que promover as atitudes e mudanças nas práticas sociais ambientais, embora de forma gradual, é possível a partir de grandes esforços e novas concepções da Educação Ambiental, a partir de diferentes ambientes educativos, como para além dos muros da escola.

Constata-se a complexidade da temática sócio-ambiental pelos inúmeros trabalhos e pesquisas realizadas na área. O envolvimento de toda a sociedade é uma tarefa 
a ser buscada pelos educadores ambientais, com novas tendências e perspectivas de aprendizado em conjunto de todos os segmentos sociais. O estudo de caso aqui proposto representa, de certa maneira, o envolvimento de toda a comunidade na busca por melhorias na condição da disposição do resíduo produzido.

\section{ESTUDO DE CASO: "Piedade sem Lixo"}

Através da pesquisa realizada no município de Piedade do Rio Grande - MG constatou-se a existência do projeto realizado pela Prefeitura Municipal, juntamente com toda sociedade civil, denominado "Piedade sem Lixo". O objetivo de tal foi promover a Coleta seletiva na cidade, envolvendo toda a população, criar uma Usina de Reciclagem e Compostagem e promover de forma integral a educação ambiental.

O município de Piedade do Rio Grande - MG fica localizado na região do Campo das Vertentes, próximo a Barbacena e São João Del Rei. De acordo com o IBGE, em 2004 a população somava 5000 (cinco mil) habitantes. A economia do município gira em torno da agricultura e pecuária. Segundo os Comitês de Bacia e o Conselho Estadual de Meio Ambiente, o município integra o GD1, ou seja, pertence ao Alto da Bacia do Rio Grande. (INSTITUTO BRASILEIRO DE GEOGRAFIA E ESTATÍSTICA, 2010). Todo o município tem 323 km2 de extensão territorial, distribuídos em três núcleos urbanos mais populosos: Piedade, Jardim e Paraíso e metade da população residindo em área rural.

Para Fernandes (2008) é política pública e responsabilidade do Estado o cuidado com a educação ambiental. Porém, a sociedade civil também cumpre o seu papel, em diálogo com as ações públicas realizadas. Na cidade de Piedade do Rio Grande existe um Conselho Municipal do Meio Ambiente composto por pessoas do município e alguns técnicos da área e tal tem a função de deliberar, consultar e fiscalizar as questões ligadas ao Meio Ambiente.

A coleta e o destino final do resíduo tem sido problema recorrente nas administrações municipais, que, por falta de um local ambientalmente adequado para a destinação final do lixo produzido, vêm improvisando soluções sempre questionadas pelas autoridades ambientais.

São vários os problemas causados pela inadequação da disposição dos resíduos, como a contaminação do solo, da água, geração de odores, proliferação de doenças e outros. E tudo isso se agrava com a tendência do crescimento da geração desses resíduos. São esses fatores e outros que levaram a administração municipal de Piedade a buscar alternativas eficazes para melhorias da disposição dos resíduos.

Nesse sentido, percebe-se através do projeto analisado no município de Piedade o envolvimento do poder público para resolver tais questões em consonância com toda a sociedade. O projeto iniciou-se com a presença de um especialista em Gestão Ambiental e Qualidade de Vida no ano de 2009, contratado pela Prefeitura para estruturá-lo. Feito isso, a dinâmica do projeto vem se desenvolvendo. Palestras, seminários, conversam com alunos da rede pública do município, com funcionários da rede de saúde, como as UBS (Unidade Básica de Saúde) e hospital, funcionários e professores de todo município, chamadas e noticiários na rádio local, cartazes afixados pelos bares e ruas da cidade: todas essas dinâmicas foram realizadas com o intuito de iniciar o debate acerca da disposição do lixo, principal problema ambiental da cidade. Uma cartilha e folders foram confeccionados e distribuídos para toda a população.

Assim sendo, a educação ambiental começou a ganhar espaço no cotidiano da população. Na escola, nas instituições públicas, no hospital, nas Igrejas e nas próprias residências o projeto foi sendo implementado e a conscientização da população quanto às vantagens da Coleta Seletiva ocorreu. O projeto foi explicado em todos os seus processos 
e a população aderiu de forma bastante significativa. Com a implementação da Coleta Seletiva, o destino final do resíduo foi modificado, passando a ser ambientalmente correto. Antes, todo o resíduo era disposto em "lixões", com o projeto, o resíduo reciclado se dirige para a Usina de Reciclagem e de lá segue seu destino final que é a comercialização.

Em números, o resíduo produzido na cidade gira em torno de 4 toneladas por dia e são do tipo domiciliar, de construção civil, comercial, público e de serviços de saúde. Não é realizada a pesagem dos caminhões de coleta, portanto, os números não são tão precisos. As estimativas do projeto consideram que $45 \%$ do resíduo possa ser reciclado, tendo então um potencial de 1,8 toneladas de material reciclável por dia ou 54 toneladas por mês. Dado o destino final do resíduo reciclado, ou seja, a sua comercialização, o projeto espera vender todo o material a um preço médio de $\mathrm{R} \$ 0,10$ (dez centavos) por quilograma, obtendo desse modo, uma receita mensal de aproximadamente $\mathrm{R} \$ 5.400,00$.

Com a visita no total de 50 (cinqüenta) residências no município, constatou-se que cerca de 35 (trinta e cinco) delas aderiram ao projeto, o que significa um número bastante expressivo. Os hábitos de todos os membros das famílias foram modificados: "agora não é simplesmente jogar o lixo no lixo", disse Fátima Barra, moradora da cidade e aderente ao projeto. Em todas que aderiram encontramos moradores dispostos a separar o resíduo.

A Usina de Reciclagem e Compostagem está em fase de construção. O resíduo reciclado é disposto no Centro de Triagem da Prefeitura, onde foram contratados três novos funcionários que fazem a separação do resíduo seco que é então comercializado, gerando lucratividade. Os resíduos comercializados são alumínios, plásticos, papelão, papel comum, pet, vidro, cobre, metal entre outros.

As fases do projeto estão sendo implantadas de forma que possam reciclar $100 \%$ do resíduo produzido no município, sendo $50 \%$ no primeiro ano - 2009, com a implantação do distrito sede, $70 \%$ no segundo ano - 2010, com a ampliação do projeto nas demais localidades, $80 \%$ no terceiro ano - 2011, com sítios e fazendas aderindo ao projeto e $100 \%$ no quarto ano -2012, com a implantação de uma unidade de separação e reciclagem, junto ao aterro controlado do município.

Observa-se que a coleta está sendo feita por pessoas recrutadas através da prefeitura segundo critérios sociais, que, após selecionadas, foram qualificadas em curso, que deram noções básicas de ecologia, meio ambiente e classificação dos diversos tipos de lixo reciclado. Todas as quartas-feiras os coletores atuam nas ruas e o lixo coletado é depositado no Centro de Triagem da Prefeitura Municipal. Nas segundas-feiras e quintasfeiras é recolhido o lixo que não é reciclável.

Acredita-se que um importante passo foi tomado no município no que tange a Educação Ambiental com a Coleta Seletiva, principalmente sobre o aspecto das mudanças comportamentais e os próprios hábitos dos moradores. No projeto, faltam medidas com maiores reflexões em relação a outros aspectos ambientais, como a preservação da mata ciliar do Rio Grande, rio que abastece todo o município e a conservação de áreas verdes dentro do próprio município. Com o objetivo de diminuir a quantidade de resíduos gerados no município mineiro de Piedade do Rio Grande, o projeto "Piedade sem Lixo" vem alcançando tal feito e, como de acordo com Tonozi-Reis (2009), contribuem para a compreensão da educação ambiental como parte de uma educação crítica, ou seja, que problematiza a complexidade dos temas ambientais.

Diante do acima exposto, a Educação Ambiental promovida em Piedade do Rio Grande está formando cidadãos críticos e reflexivos, capazes de perceberem a realidade que vivem. 


\section{CONCLUSÃO}

Através dessa revisão de literatura e do estudo de caso aqui proposto, podemos concluir que o impacto do homem sobre o meio ambiente tem tido conseqüências agravantes, mas, através da busca por uma Educação Ambiental disposta a envolver todos os membros da sociedade, tais efeitos podem ser revertidos, criando soluções juntamente com o desenvolvimento sustentável do planeta. A cidadania plena passa necessariamente pelo exercício da educação ambiental como se verificou com o Projeto "Piedade sem Lixo" e a sua realização.

Com a mobilização de toda a comunidade de Piedade do Rio Grande para a separação do lixo em casa, os ganhos obtidos com o projeto vêm se tornando visíveis, com a diminuição considerável dos resíduos, a preservação da natureza e ainda a possibilidade de renda para algumas famílias. A divulgação do projeto foi feita de forma interessante, atingindo toda a comunidade, inclusive a zona rural, que ainda não participa ativamente do projeto, mas vem requerendo junto à Prefeitura Municipal a Coleta Seletiva em tais áreas, o que demonstra a participação popular no projeto e o exercício pleno da cidadania.

Em todas as casas visitadas encontramos os folders e as cartilhas que explicam passo a passo o que cada morador deve fazer. Os funcionários recrutados para a coleta foram qualificados em curso e o Centro de Triagem comercializa todo o material coletado. A Usina de Reciclagem e Compostagem está em fase de construção. De maneira bem simples, através da Coleta Seletiva e de um desenvolvimento de uma Educação Ambiental, Piedade do Rio Grande vem diminuindo a quantidade de resíduos, transformando o espaço social dos moradores, participantes ativos do projeto e responsáveis pelo florescimento de uma ética ambiental responsável. Ainda há muito o que se fazer, mas, os primeiros passos foram iniciados.

\section{REFERÊNCIAS}

ABRÃO, Ana Luísa de Almeida Batista Martins et al. Proposta alternativa para a coleta seletiva de resíduos sólidos urbanos na cidade de Campo Grande/MS, valorizando a participação dos catadores. In: CONGRESSO INTERAMERICANO DE ENGENHARIA SANITÁRIA E AMBIENTAL, 27., 2000, Campo Grande / MS. Anais eletrônicos... Campo Grande / MS: [s. n. ], 2000.

BRUGGER, Paula. O vôo da águia: reflexões sobre o método, interdisciplinaridade e o meio ambiente. Educar. [S.I] n.27. p. 75-91, 2006. ISSN 0104-4060.

CARVALHO, José Murilo. Cidadania no Brasil: o longo caminho. Rio de Janeiro: Civilização Brasileira, 2002.

CARVALHO, L.M. et al. Meetings in Environmental Education Research: routes (20012008) and tendencies in research related to school and comunity context. In: WORLD ENVIRONMENTAL EDUCATION CONGRESS, 5., 2009, Montreal - Canadá. Annals...: Montreal, Canadá, 2009.

CIDIN, Renata de Costa Pereira Jannes; SILVA, Ricardo Siloto. Pegada Ecológica: Instrumento de Avaliação dos impactos antrópicos no meio natural. Estudos geográficos, Rio Claro, n.2. v.1, p. 43-52, jun. 2004. ISSN 1678-698X. Disponível em: < www.rc.unesp. $\mathrm{br} /$ igcc/gad/geografia/revista.htm>.

DUBOIS, Jean C.L. Conteúdo da Palestra apresentada durante "VI Encontro de Educação Ambiental do Estado do Rio de Janeiro". CREA-RJ 26-29 de Julho de 1999

FAGUNDES, Diana da Cruz. Gerenciamento de resíduos sólidos urbanos em Tarumã e Teodoro Sampaio - SP. Sociedade \& Natureza, Uberlândia - SP, v. 21. n. 2. , ago. 2009. ISSN 1982-4513. 
FERNANDES, Antônio Edimir Frota. A Educação Ambiental, o papel do Estado e as Políticas Públicas no Brasil. Revista Gestão Universitária. 215 ed.,ago. 2008. ISSN 1984-3097.

FERNANDEZ, F.A.S. Aprendendo a lição de Chaco Canyon: do "Desenvolvimento Sustentável" a uma Vida Sustentável. Texto baseado em palestra proferida em 30 de junho de 2004, na Conferência Nacional 2004 - Empresas e Responsabilidade Social, promovida pelo Instituto Ethos, em São Paulo, e atualizado pelo autor em junho de 2005.

FRANÇA, Rosiléa Garcia: RUARO, Édina Cristina Rodrigues. Diagnóstico da disposição final dos resíduos sólidos urbanos na região da Associação dos Municípios do Alto Irani (AMAI), Santa Catarina. Ciência e Saúde Coletiva, Rio de Janeiro, v. 14. n.6., dez. 2009.

INSTITUTO BRASILEIRO DE GEOGRAFIA E ESTATÍSTICA. Dados demográficos dos municípios brasileiros: apresenta informações censitárias dos municípios brasileiros. [S.I.], 2007. Disponível em: <http://www.ibge.com.br/>. Acesso em: 11 fev. 2010.

.Cidades: População estimada, 2004. Disponível em: <http://www.ibge.gov.br/ icadesat/default.php>. Acesso em: 10 fev. 2010.

JACOBI, Pedro. Educação Ambiental, Cidadania e Sustentabilidade. Caderno de Pesquisa, n.118, p. 189-205, mar. 2003

JUNKES, M. B. Procedimentos para aproveitamento de resíduos sólidos urbanos em municípios de pequeno porte. Originalmente apresentada como dissertação de mestrado, Programa de Pós-graduação em Engenharia de Produção. Universidade Federal de Santa Catarina, 2002.

KAWASAKI, Clarice Sumi. CARVALHO, Luiz Marcelo. Tendências da pesquisa em Educação Ambiental. Educação em Revista, Belo Horizonte, v.25, n. 3., dez. 2009. Disponível em: $<$ www.scielo.com >.

LAMPERT, Ernani. Educação e MERCOSUL: desafios e perspectivas. Revista da Faculdade de Educação, São Paulo, v. 24, n 2., jul. / dez. 1998. ISSN 0102-2555.

LAYARGUES, Philippe. O cinismo da reciclagem: o significado ideológico da reciclagem da lata de alumínio e suas implicações para a educação ambiental. In: LOUREIRO, F.; LAYARGUES, P.; CASTRO, R.(Orgs.) Educação ambiental: repensando o espaço da cidadania. São Paulo: Cortez, 2002. p. 179-220.

LEFF, E. Epistemologia ambiental. São Paulo: Cortez, 2001.

LIMA. Gustavo Ferreira da Costa. Questão ambiental e educação: contribuições para o debate. Ambiente \& Sociedade. NEPAM/UNICAMP. Campinas, ano 2, n.5, p. 135-153, 1999.

O discurso da sustentabilidade e suas implicações para a educação. Ambiente \& Sociedade. NEPAM/UNICAMP. Campinas, v. 6, n 2, jul. / dez., 2003. ISSN 1414-753X.

MENEGUZZO, Isonel Sandino. CHAICOUSKI, Adeline. MENEGUZZO, Paula Mariele. Desenvolvimento Sustentável: desafios à sua implantação e a possibilidade de minimização dos problemas sócio-ambientais. Revista Eletrônica do Mestrado em Educação Ambiental. PPGEA/FURG-RS. Rio Grande do Sul, v. 22, jan./ jul., 2009. ISSN 1517-1256

MÜLLER, G. In: BECHER, D.F. (Org). Desenvolvimento sustentável: necessidade e/ou possibilidade? 3. ed. Santa Cruz do Sul: Edunisc, p. 238, 2001.

PASINATO, Raquel. Educação Ambiental: algumas reflexões conceituais. In: ENCONTRO AMERICANO DE PÓS-GRADUAÇÃO, 4., Paraíba. Anais eletrônicos... Paraíba, [20--?] p. 37-50.

PENNA, C.G. O Estado do Planeta: sociedade de consumo e degradação ambiental. Rio de Janeiro: Record, 1999. 
SAVI, J. Gerenciamento integrado de resíduos sólidos urbanos em Adamantina-SP: análise da viabilidade da usina de triagem de RSU com coleta seletiva. Originalmente apresentado como tese de doutorado, Faculdade de Ciências e Tecnologia, Universidade Estadual Paulista Presidente Prudente, 2005. 236f.

SORRENTINO, M. De Tbilisi a Tessaloniki, a educação ambiental no Brasil. In: JACOBI, P. et. al. (orgs.). Educação, meio ambiente e cidadania: reflexões e experiências. São Paulo: SMA, 1998. p. 27-32.

TAMAIO, I. A. A mediação do professor na construção do conceito da natureza. Originalmente apresentado como dissertação de mestrado, Faculdade de Educação, UNICAMP, 2000.

TONOZI-REIS, Marília Freitas de Campos. Algumas publicações e pesquisas sobre educação ambiental. Caderno CEDES. v. 29. n. 77., jan. / dez. 2009.

VASCONCELOS, Hedy Silva Ramos et al. Espaços Educativos impulsionadores da educação ambiental. Caderno CEDES. v. 29, n. 77, jan. / dez. 2009. 